\title{
PATIENT AND OBSERVER SCAR ASSESSMENT FOLLOWING BASAL CELL CARCINOMA SURGERY: MULTICENTER QUASI EXPERIMENTAL STUDY
}

\author{
Moizza Tahir, Ghazanfar Ali, Najia Ahmad*, Jauhar Mumtaz Khan**, Sakina Sadiq Malik***, Muhammad Ali Tahir**** \\ Combined Military Hospital Multan/National University of Medical Sciences (NUMS) Pakistan, *Pakistan Naval Ship Shifa Hospital, Karachi Pakistan, \\ **Ali Medical Centre, Islamabad Pakistan, Pakistan, ***Combined Military Hospital/National University of Medical Sciences (NUMS) Rawalpindi Pakistan, \\ ****Jinnah Post Graduate Medical Centre, Karachi Pakistan
}

ABSTRACT

Objective: To assess patient and observer reported scar quality after Basal cell carcinoma surgery of face using the Patient and Observer Scar Assessment Scale (POSAS).

Study Design: Quasi experimental study.

Place and Duration of Study: Dermatology Department, Tertiary Care Hospitals at Multan and Karachi and Plastic Surgery Department, Tertiary Care Hospital Multan, from Apr to Sep 2020.

Methodology: Patients with basal cell carcinoma that full filled inclusion and exclusion criteria were enrolled by consecutive sampling technique at Dermatology and Plastic Surgery Department after informed consent. Surgical excision was followed by reconstruction of defect either by direct closure or by rotation or advancement flap. Surgical scar was assessed independently at 8 weeks by POSAS. Data was analyzed with SPSS-23.

Results: A total of 27 patients were enrolled in study. There were 11 (37.9\%) males and $16(59.25 \%)$ females between ages of 45-70 years. Basal cell carcinoma was located on cheek in $15(55.5 \%)$, nose in $9(33.3 \%)$, temple $2(7.4 \%)$ and forehead $1(3.7 \%)$ cases. Direct closure was performed in $6(22.2 \%)$, rotation flaps in $10(40.7 \%)$, and advancement flaps in $11(40.7 \%)$ cases. Mean score of observer opinion about surgical scar between different surgical techniques was not statistically significant $(p=0.191)$. However, mean score of patient opinion of scar between different surgical techniques was statistically significant $(p=0.032)$.

Conclusion: POSAS is a valid tool for scar evaluation by patient and observer-reported scar qualities after Basal cell carcinoma surgery.

Keywords: Basal cell carcinoma (BCC) scar, Patient and observer scar assessment scale (POSAS), Scar quality, Surgical scar assessment.

How to Cite This Article: Tahir M, Ali G, Ahmad N, Khan JM, Sadiq S, Tahir MA. Patient and Observer Scar Assessment Following Basal Cell Carcinoma Surgery: Multicenter Quasi Experimental Study. Pak Armed Forces Med J 2021; 71(6): 2232-2235. DOI: https://doi.org/10.51253/pafmj.v71i6.6820

This is an Open Access article distributed under the terms of the Creative Commons Attribution License (https://creativecommons.org/licenses/by-nc/4.0/), which permits unrestricted use, distribution, and reproduction in any medium, provided the original work is properly cited.

\section{INTRODUCTION}

Basal cell carcinoma (BCC) is one of the common non-melanoma skin cancers (NMSC) worldwide. Its incidence is on the rise. ${ }^{1}$ Its morbidity is attributable to local tissue invasion and destruction. ${ }^{2}$ Ultraviolet radiation (UVR) and genetic predisposition are considered as most important cause. BCC are most common in fifth and sixth decades of life. It occurs in areas of chronic sun exposure and $74 \%$ are found on head and neck. Since it does not interfere with routine activities, therefore medical consultations are delayed in initial phase of tumor progression. ${ }^{3}$ They are slow growing tumors which rarely metastasize. Incomplete removal results in local destruction and disfigurement. ${ }^{4}$

A variety of surgical and non- surgical modalities are used for BCC treatment. Management is based on tumor location, patient age, comorbidities and the type of tumor involved. Standard Surgical Excision (SE)

Correspondence: Dr Moizza Tahir, Associate Professor, Dermatology Department, Combined Military Hospital Gujranwala Pakistan Received: 01 Jun 2021; revision received: 13 Aug 2021; accepted: 27 Aug 2021 and Mohs' Micrographic surgery (MMS) are used for treatment of BCC. Breuninger and Dietz in their study of 2016 BCCs found that in small (<10mm diameter) tumours, excision of $2 \mathrm{~mm}$ peripheral surgical margin cleared $70 \%$, $3 \mathrm{~mm}$ margin cleared $84 \%$ and $5 \mathrm{~mm}$ margin cleared $95 \%$ of tumour. ${ }^{5}$ Recurrence rate of BCC after standard SE ranged from $3.2-10 \%$ for primary tumor and $>17 \%$ for recurrent BCC. Recurrence after incomplete SE is up to $50 \%$. MMS remains an ideal strategy for high cure rate and tissue conservation. However recurrence of tumor after MMS is reported as $1-3 \%$ in primary and $5-7 \%$ for recurrent tumors. ${ }^{6}$

The impact of facial skin cancer surgery on patients' perceived aesthetic appearance is not well understood. ${ }^{7}$ Data about aesthetic evaluation of scar after NMSC surgery is limited as no validated Patient Reported Outcome Measures (PROMs) were employed. Patient and Observer Scar Assessment Scale (POSAS) is a reliable tool to evaluate scar. ${ }^{8}$ POSAS has two numeric scales: the patient scale and the observer scale. It has six items that are scored on a 10-point scale $(1=$ like 
normal skin, 10=worst scar imaginable) giving a "total score" range of 6-60 and an "overall opinion" range of 1-10. It documents vascularity, pigmentation, thickness, relief, pliability, and surface area. This scale includes patients' perspective of pain, itch, color, stiffness and thickness. The usefulness of POSAS in dermatological surgery has not been assessed. ${ }^{9}$ Present study aims to evaluate the usefulness of POSAS in facial skin surgical scars in BCC patients. It will also document bcc clearance of tumor and its closure.

\section{METHODOLOGY}

This quasi-experimental study was conducted at the Department of Dermatology of Tertiary Care Hospitals of Multan and Karachi and at Plastic Surgery Department, Tertiary Care Hospital Multan, from April to September 2020. Hospital ethical committee's approval (ERC/2021/Dermatology/47) was taken. We calculated a sample size of 27 patients, using World Health Organization sample size calculator. ${ }^{10}$ Twenty seven patients were enrolled by consecutive sampling technique after the informed consent.

Inclusion Criteria: Clinically diagnosed patients of basal cell carcinoma were included.

Exclusion Criteria: Patients who had surgery for NMSC in past or had treatment earlier with cryotherapy, cautery, topical Imiquimod, 5-Fluorouracil or Photodynamic therapy were excluded.

All the patients were treated by fellows of Dermatology \& Plastic surgery. Patients' age, gender, occupation, tumor location and surgical closure technique were recorded. Patients were photographed in bright illumination. They were counseled about procedural details. Surgical resections of BCC were performed. Resected tumor margins were marked as superior, inferior, medial, deep and lateral using silk sutures. Defects were assessed for wound closure. Small defects were closed directly, whereas large defects were addressed using island pedicle flap, advancement flap and rotation flaps. Perioperative photographs were taken. Tissue was dispatched to laboratory for margin clearance. Histopathology report was collected and reviewed for margin and depth clearance. Tumor clearance was recorded. Re-excision was done where margins were involved and again submitted for histological clearance.

At 8 weeks after the procedure, esthetic outcomes of scar were assessed by the patient and surgeons by the POSAS scale. Patients were explained POSAS scale for marking. The patient and surgeon independently completed the POSAS scale.
Data were analyzed using Statistical Package for Social Sciences (SPSS) version 23. The qualitative variables were presented as frequency and percentage. Data was stratified on the basis of surgical closure techniques. Mean and standard deviation were calculated for observer's opinion on parameters of vascularity, pigmentation, thickness, relief, pliability, and surface area and for patient's perspective on parameters of pain, itch, color, stiffness and thickness. Mean score of observer and patient's opinion between surgical techniques groups was compared using one-way ANOVA test $p$-value of $\leq 0.05$ was considered statistically significant.

\section{RESULTS}

In this study 27 patients of BCC on the face were included. Thirteen had surgical excision at Dermatology Department, 7 at Plastic Surgery Department at Multan. Seven received treatment at Dermatology Department Karachi. There were 11 (37.9\%) males and $16(59.25 \%)$ females between ages of $45-70$ years mean age was $56.63 \pm 7.71$ years. There were $17(62.96 \%)$ house wives and $10(37.03 \%)$ were retired soldiers. BCC was located on the cheek in $15(55.50 \%)$, nose in $9(33.30 \%)$, temple $2(7.40 \%)$ and forehead $1(3.70 \%)$ cases. Direct closure was performed in $6(22.20 \%)$, rotation flaps in $10(40.70 \%)$, and advancement flaps in 11 $(40.70 \%)$. Surgical techniques of direct closure (Figure$1 \mathrm{a}, \mathrm{b} \& \mathrm{c}$ ), rotation flap (Figure-2 a \& b), and advancement flap (Figure-3 a \& b).

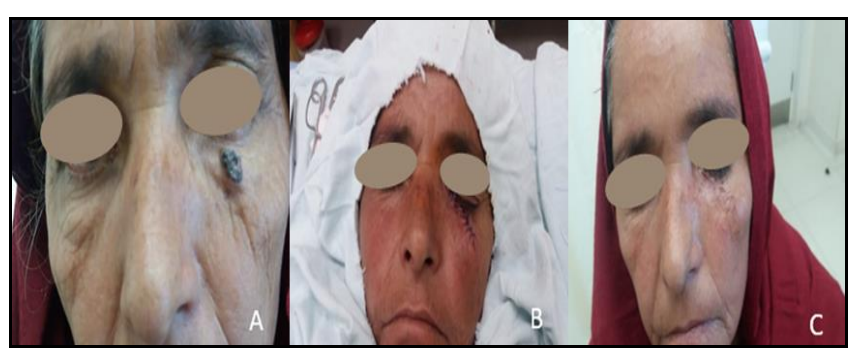

Figure-1: a) Bassal Cell Carcinoma, (b) Direct closure, c): Scar at 8 weeks.

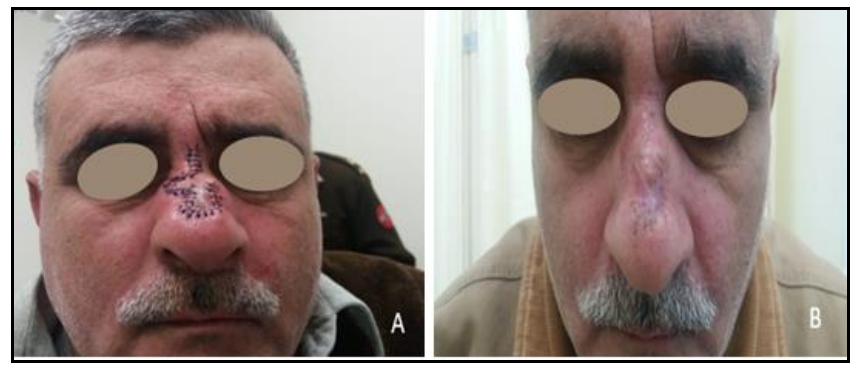

Figure-2: a): Rotational Flap following BCC Surgery Nose, b) Scar at 8 weeks. 


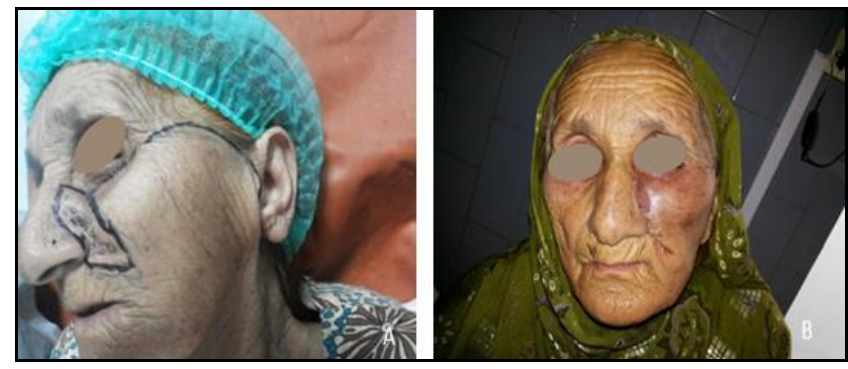

Figure-3: a): BCC reconstruction plan with cheek advancement flap, b): Scar at 8 weeks.

POSAS was used at $8^{\text {th }}$ weeks. Patient score for variables of texture, irregularity, stiffness, color itch and pain for rotation, advancement flaps and direct closure are shown in (Figure-4). Observer component of POSAS for surgical techniques on parameters of pliability; surface area relief, thickness, pigmentation and vascularity are shown in (Figure-5).

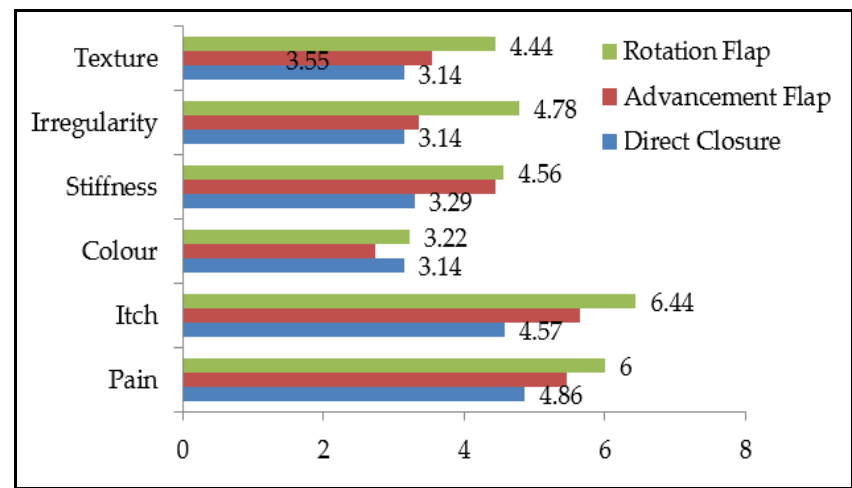

Figure-4: Patient component of POSAS for surgical techniques of direct closure, advancement and rotation flaps.

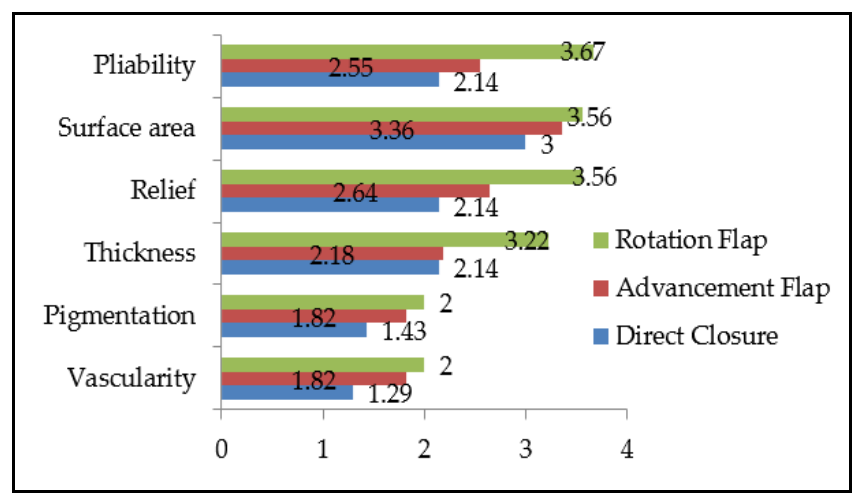

Figure-5: Observer component of POSAS on surgical techniques of direct closure, advancement and rotation flaps.

Mean score of observer opinion between surgical techniques was not statistically significant $(p=0.191)$. However, mean score of patient opinion between different surgical techniques was statistically significant $(p=0.032)$ (Table).
Table: Opinion of observer and patient on POSAS scale between different surgical techniques.

\begin{tabular}{l|c|c|c|c}
\hline $\begin{array}{l}\text { Opinion } \\
\text { on } \\
\text { POSAS }\end{array}$ & $\begin{array}{c}\text { Direct } \\
\text { Closure } \\
\text { (Mean } \pm \text { SD) }\end{array}$ & $\begin{array}{c}\text { Rotation } \\
\text { Flap } \\
\text { (Mean } \pm \text { SD) }\end{array}$ & $\begin{array}{c}\text { Advance- } \\
\text { ment Flap } \\
\text { (Mean } \pm \text { SD) }\end{array}$ & $\begin{array}{c}\boldsymbol{p} \text { - } \\
\text { value }\end{array}$ \\
\hline Observer & $2.14 \pm 1.46$ & $4.11 \pm 2.80$ & $3.18 \pm 1.66$ & 0.191 \\
\hline Patient & $8.86 \pm 0.69$ & $7.67 \pm 0.87$ & $8.36 \pm 6.92$ & 0.032 \\
\hline
\end{tabular}

\section{DISCUSSION}

BCC is the most common malignant skin tumor reported in Pakistan. ${ }^{11}$ In our study adults between $45-$ 70 years had BCC and commonest site was cheek followed by nose. BCC more commonly involved elderly population, however it has been reported in adults younger than 50 years, ${ }^{12} \mathrm{Li}$ et al reported bcc in sun exposed skin in Asian adult's age 11-99 years with mean 71.8 years. They documented nose and its surrounding $(29.5 \%)$ as commonest site followed by cheeks and zygomatic area in (13.9\%). ${ }^{13}$

Surgery is the best choice of treatment with lowest failure rate. Recommended surgical margin at excision is 3-4 $\mathrm{mm}$ for low risk BCCs, whereas a clinical excision margins of 5-10 $\mathrm{mm}$ are recommended for intermediate- to high-recurrence risk BCCs. ${ }^{14}$ Outcome of surgical excision is scar; quality of that scar is assessed by the patient and the investigator by POSAS. Difference of opinion in scar parameters of patient and observer exist in our study. This finding is consistent with Weitemeyer et al, study on wide local excision scars for melanoma. Zhang et al. in systematic review found that patients and physicians perception of surgical scar is different. ${ }^{16}$ Medical professionals may underestimate the significance of physical appearance and hence psychosocial impairment from scarring in patients with skin cancer. ${ }^{17}$ Large number of measures of POSAS share 10 item score response that may cause biases. ${ }^{18}$ Observer assessment parameters are influenced by scar characteristics whereas patients are more inclined towards scar symptoms such as scar pain and itch. Difference in scar quality parameters between surgeons and patients are important to understand. Validated PRO tools identify patients concerns. Appropriate counseling and support by the medical practitioners will improve patient care.

Lee $e t$ al. in a qualitative study on aesthetic procedures and health related concerns of patient's perspective after BCC surgery reported aesthetic outcomes were secondary but had important effects on the participant's social and psychological functioning. The conceptual framework provided the basis for the development of a patient reported outcome instrument. ${ }^{19}$ These instruments help in shared-decision making and en- 
able physician to precisely communicate expected outcomes of treatment. Physician's better understanding of BCC surgery scar will improve process of informed consent and patient's counseling and support.

\section{ACKNOWLEDGEMENT}

Authors acknowledge contribution of Zainab Ansari Medical student $1^{\text {st }}$ year MBBS for data analysis using computer software SPSS

\section{LIMITATION OF STUDY}

Limitation of our study was short follow-up period (8 weeks). Aesthetic results and functional deficits may gradually improve with time. Since our study has shown good esthetic outcome of surgery at early evaluation so later evaluation would probably not alter the results of our study. All of our patients were from rural background; urban population would have rendered diverse results. Patient and observer scar assessment scale (POSAS) tool however does not curtail influence of scars on patients' quality of life.

\section{CONCLUSION}

Patient and observer scar assessment scale is a valid tool for scar evaluation by patient and observer reported scar qualities after BCC surgery. Disagreement may occur between physician and patient reported scars assessments.

\section{Conflict of Interest: None.}

\section{Authors' Contribution}

MT: Direct, Intellectual conception, design, work, GA: Direct, Intellectual conception, design, work, NA: Direct, Intellectual conception, design, work, JMK: Data analysis, SS: Data analysis, MAT: Data analysis, interpretation.

\section{REFERENCES}

1. Ramdas K, Van-Lee C, Beck S, Bindels P, Noordhoek- Hegt V. Differences in rate of complete excision of basal cell carcinoma by dermatologists, plastic surgeons and general practitioners: a large cross-sectional study. Dermatol 2018; 234(3-4): 86-91.

2. Rhodes LE, de-Rie M, Enström Y. Photodynamic therapy using topical methyl aminolevulinate vs surgeryfor nodular basal cell carcinoma results of a multicenter randomized prospective trial. Arch Dermatol 2004; 140(1): 17-23.

3. Daniel H. Quality of life in basal cell carcinoma patients in Brazil: A pilot cross sectional study. Dermatol Surg 2013; 39(4): 620-626.

4. Smeets NWJ, Kuijpers DIM, Nelemans P, Ostertg JU, Verhaegh MEJM, Gamkahamn M. Micrographic surgery for treatment of basal cell carcinom of face results of a retrospective study and review of the literature. Br J Dermatol 2004; 151(1): 141-147.
5. Breuninger DK. Prediction of subclinical tumor infiltration in basal cell carcinoma. J Dermatol Surg Oncol 1991; 17(7): 574578.

6. Leibovitch I, Huilgol SC, Selva D, Richards PR. Basal cell carcinoma treated with Mohs surgery in Australia II. Outcomes at 5year follow-up. J Am Acad Dermatol 2005; 53(3): 452-457.

7. Kant SB, Mosterd K, Kelleners-Smeets NWJK, der-Hulst PA. Measuring aesthetic results after facial skin cancer surgery by means of the FACE-Q. Eur J Plast Surg 2020; 43(5): 541-548.

8. Chae JK, Kim JH, Kim EJ, Park K. Values of a patient and observer scar assessment scale to evaluate the facial skin graft scar. Ann Dermatol 2016; 28(5): 615-623.

9. Raklyar ZD. Use of a patient and observer scar assessment scale to evaluate the VY advancement flap for reconstruction of medial cheek defects. Dermatol Surg 2012; 38(12): 19681974.

10. Sarfraz T, Tariq H, Ifthikhar N, Raza N, Malik NA, Khan SA. Frequency and Histological Pattern of Malignant Skin Lesions In Pakistani Population. Pak Armed Forces Med J 2019; 69(1): 8386.

11. Soomro FR, Bajaj DR, Abbasi P, Hussain AS. Cutaneous malignant tumors: A profile of ten years at LINAR, Larkana-Pakistan. J Paki Assoc Dermatol 2010; 20(3): 133-136.

12. Kim DP, Kus KJB, Ruiz E. Basal cell carcinoma review. Hematol Oncol Clin North Am 2019; 33(1): 13-24.

13. Li CL, Chen YC, Yang KC, Chen LW. Different histopathologic profiles and outcomes between sun-exposed BCC and non-sunexposed BCC. Sci Rep 2020; 10(1): 1-8.

14. Ofaiche J, Lopez R, Bérard E, André A, Bulai-Livideanu C, Méresse T, et al. Surgical treatment of facial basal cell carcinoma: patient-based assessment of clinical outcome in a prospective cohort study. Dermatol 2017; 232(5): 550-557.

15. Weitemeyer MB, Bramsen P, Klausen TW, Hölmich LR, Gjorup CA. Patient-and observer-reported long-term scar quality of wide local excision scars in melanoma patients. Plast Reconst Surg 2018; 52(6): 319-324.

16. Zhang J, Miller CJ, O'Malley V, Bowman EB, Etzkorn JR, Shin TM, et al. Patient and physician assessment of surgical scars a systematic review. JAMA Facial Plast Surg 2018; 20(4): 314-323.

17. Sobanko JF, Sarwer DB, Zvargulis Z, Miller CJ. Importance of physical appearance in patients with skin cancer. Dermatol Surg 2015; 41(2): 183-188.

18. Kantor J. Reliability and photographic equivalency of the scar cosmesis assessment and rating (SCAR) scale, an outcome measure for postoperative scars. JAMA Dermatol 2017; 153(1): 55-60.

19. Lee EH, Anne F, Klassen-Jessica L. Lawson AMSLP. Patient experiences and outcomes following facial skin cancer surgery: a qualitative study. Australas J Dermatol 2016; 57(3): e100-104. 